\title{
Ethics for today - For physicians and the Canadian Paediatric Society
}

The principles espoused in the Hippocratic Oath and passed down through generations of physicians over the millennia remain the core for the ethical behaviour of physicians today (<www.indiana.edu/ ancmed/oath.htm $>$ ). These traditional values have been expanded and clarified in the current day to cover the fundamental principles of medicine for physicians; especially, compassion, beneficence, nonmaleficence, and respect for persons and justice (Canadian Medical Association's Code of Ethics $<$ www.the-cma.org/consumer/ethics.cfm>). Codes are not exhaustive and, by their nature, need to be interpreted in context. In this issue of Paediatrics $\mathcal{E}$ Child Health, articles address contemporary ethical issues around compassion and justice, such as obstacles to drugs access for children with inflammatory bowel disease discussed by Otley et al (pages 87-88), and issues of respect for persons and confi- dentiality concerns in regards to the reporting of clinical cases discussed by Shevell (pages 83-84). The article by Muirhead (pages 85-86) highlights ethical issues that arise when parents and physicians disagree on management. Each of these articles deals with our ethical practice as a physician. In contrast, Moreau (pages 81-82) reports on the development of the Code of Ethics for the Canadian Paediatric Society. This is not a code that outlines the principles for our behaviour as individual physicians caring for children and youth. This code moves us further along the ethical pathway by providing the ethical principles the Canadian Paediatric Society should use in making decisions, including those that involve policy.

Noni MacDonald MD FRCPC Co-Editor-in-Chief

\section{Ethics and accountability in the Canadian Paediatric Society}

\author{
Elizabeth Moreau BA MM
}

A ccountability has become the watchword of the Canadian voluntary sector in recent years. Particularly since the release of the 1999 report of the Panel on Accountability and Governance in the Voluntary Sector (1), chaired by former New Democratic Party leader Ed Broadbent, charities and other not-for-profit organizations have faced internal and external pressures to demonstrate effectiveness and show stakeholders that they are indeed fulfilling their missions and mandates.

Accountability involves much more than balance sheets or program reports. Voluntary sector organizations like the Canadian Paediatric Society (CPS) are complex systems accountable to an increasing number of different populations for a variety of activities. The CPS is active in professional development, providing health information for professionals and the public, public policy advocacy, and much more. We're responsible to members, government, corporate sponsors, the wider health care community and the public at large, all of whom look to the CPS to help make decisions about children's health.

As an organization representing physicians and providing health information, the CPS is in a position of public trust. Like other voluntary sector organizations, we are selfgoverning, run by a board of directors. To really demonstrate accountability, we must continue to improve our stakeholders' understanding of what we do and how we do it. We need policies and procedures that are transparent, sound governance practices that ensure effective organizational stewardship, and meaningful mechanisms for evaluating programs and reporting results.

Organizations like the CPS are effective because of the hundreds of people who devote their time and energy to making it work. Paediatricians and others from across the country - such as members of the Board of Directors and committees, the Paediatrics $\mathcal{E}$ Child Health editorial board, spokespeople and expert reviewers - contribute their 
expertise and energy to allow the CPS to function as an advocate for children and youth. All of these people bring with them their own values and experiences, which is both priceless and problematic. How can the organization ensure that regardless of one's personal ethics, everyone working on its behalf upholds a certain ethical standard?

One of the tools the Broadbent report recommends that organizations have in their 'accountability toolbox' is a code of conduct (1). As practicing paediatricians, CPS members already have a code of ethics to guide them. Physicians adhere to a largely self-regulated yet comprehensive set of ethical standards developed by the Canadian Medical Association. The Canadian Medical Association's Code of Ethics (2) details 43 responsibilities, to the patient, society and the medical profession. However, although the code is designed to govern the behaviour of individual physicians, it does not address responsibilities in the context of a volunteer professional association.

While many associations have developed professionspecific codes of ethics, few have addressed the needs of the organizations themselves. The CPS recently became one of these few when, in November 2003, it approved an organizational code of ethics that articulates a set of standards for the organization, its volunteers and staff. The year-long development process involved the Board of Directors and committee representatives, as well as broad-based consultation with members at large. The goal was to develop a document that would reflect the values of the organization and help everyone working on behalf of the CPS to make ethically sound decisions. The code is also intended as an expression of our mission, and as a tool to help us continue to work toward that mission.

To develop the code, we looked at the range of issues facing the CPS that have ethical dimensions. There are many: How should we deal with conflicts of interest among volunteers? How do we ensure that our program and advocacy priorities are in the best interests of children and youth? Who speaks on behalf of the organization? How do we evaluate the appropriateness of our corporate sponsors? These are just a few of the issues facing the CPS.

The code is comprehensive, addressing areas such as governance, financial accountability, public affairs and communications, public policy advocacy, medical and professional affairs, fundraising and human resources. It describes specifics such as how the Board should function, the principles of professional development and the parameters of fundraising.

The code is but one tool among many to ensure accountability, and it is not an end in itself. Perhaps even more crucial are evaluation and implementation frameworks that will allow the code to become a living document - part of the organization's day-to-day operations - so that questions about ethics are as routine as questions about budget or deadlines. These elements will be developed over the coming year and will continue to evolve to meet the changing needs of the environment we work in.

In the meantime, all areas of the CPS, including Paediatrics $\mathbb{E}$ Child Health, can begin the process by reviewing current policies and procedures in light of the code and determining the need for new policies where none currently exist. It's a way of taking the ethical pulse of our activities and seeing how we measure up.

No document can provide the answer to every difficult question. Rather, our code of ethics is intended as a guide to moral decision-making and ethical policy formation. Its aim is to offer guidance as we work to find solutions to difficult issues and moral dilemmas. Our hope is that this code will also stimulate conversation and debate, and contribute to an organizational climate that encourages meaningful and thoughtful inquiry about complex ethical issues.

The CPS Code of Ethics is available online at $<w w w . c p s . c a>$.

ACKNOWLEDGEMENTS: Funding for the development of the Canadian Paediatric Society Code of Ethics was provided by a grant from the McConnell Family Foundation, as part of the McGill-McConnell Program for National Voluntary Sector Leaders. Development of the Code of Ethics was led by the following advisory committee members: Ms Marie Adèle Davis, Ms Jill Greenwell, Dr Bob Issenman, Ms Melanie Laffin, Dr Denis Leduc, Dr Doug McMillan, Mr Paul Muirhead and Dr Diane Sacks.

\section{REFERENCES}

1. Panel on Accountability and Governance in the Voluntary Sector. Building on Strength: Improving Governance and Accountability in Canada's Voluntary Sector. February 1999. <www.vsr-trsb.net/pagvs/> (Version current at January 19, 2004).

2. Canadian Medical Association. Code of Ethics of the Canadian Medical Association. Ottawa: Canadian Medical Association, October 15, 1996. <www.cma.ca/cma/common/displayPage.do? pageId=/staticContent/HTML/NO/12/inside/policybase/1996/10 15.htm $>$ (Version current at January 19, 2004). 